LETTER TO THE EDITOR

\title{
Function of human mineralocorticoid receptor splice variant
}

V Bähr, C Bumke-Vogt, J Götze, A F H Pfeiffer and S Diederich

Department of Endocrinology, Diabetes and Nutrition, Charité-University Medicine Berlin, Campus Benjamin Franklin, Hindenburgdamm 30, 12200 Berlin, Germany

(Correspondence should be addressed to V Bähr; Email: volker.baehr@charite.de)

In their recent paper, Pascual-Le Tallec et al. (1) state that a publication by Bloem et al. (2) describes that a mineralocorticoid receptor (MR) splice variant with a $12 \mathrm{bp}$ insertion coding for a protein with four additional amino acids $(\mathrm{MR}+4)$ shows no functional difference to the MR without insertion. This evidence is not produced in the publication by Bloem et al. or to our knowledge anywhere else. On the contrary Bloem et al. propose that the additional four amino

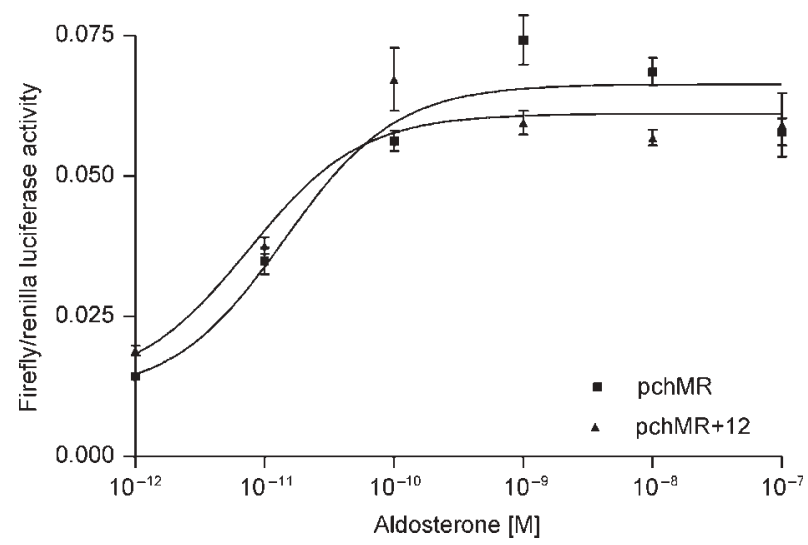

Figure 1 Aldosterone produced a concentration-dependent transactivation of the reporter gene. Half the maximal transactivation $\left(E D_{50}\right)$ was achieved near log $-11 \mathrm{M}$ aldosterone regardless of whether hMR or hMR+ 4 was expressed. There was a tendency toward a slightly lower $\mathrm{ED}_{50}$ (higher sensitivity) and somewhat weaker transactivation when MR+4 was expressed. The data justify the statement by Pascual-Le Tallec et al. (1) that the function of hMR+ 4 is comparable to that of hMR. acid residues in the DNA binding domain could alter binding to a glucocorticoid response element (GRE) and transcription activation. Because this splice variant shows considerable concentrations in various human tissues (3), we have compared transactivation mediated by MR and MR+4. The plasmid pchMR+12 coding for $\mathrm{hMR}+4$ was created by in vitro PCR mutagenesis of pchMR coding for hMR. Transactivation of both variants by aldosterone was analysed in CV-1 cells by measuring firefly luciferase activity of an inducible reporter gene normalised to the activity of constitutively expressed renilla luciferase (Fig. 1) (4).

\section{References}

1 Pascual-Le Tallec L, Demange C \& Lombes M. Human mineralocorticoid receptor A and B protein forms produced by alternative translation sites display different transcriptional activities. European Journal of Endocrinology 2004150 585-590.

2 Bloem LJ, Guo C. \& Pratt JH. Identification of a splice variant of the rat and human mineralocorticoid receptor genes. Journal of Steroid Biochemistry and Molecular Biology 199555 159-162.

3 Wickert L, Watzka M, Bolkenius U, Bidlingmaier F \& Ludwig M. Mineralocorticoid receptor splice variants in different human tissues. European Journal of Endocrinology 1998138 702-704.

4 Grossmann C, Scholz T, Rochel M, Bumke-Vogt C, Oelkers W, Pfeiffer AFH, Diederich S \& Bähr V. Transactivation via the human glucocorticoid and mineralocorticoid receptor by therapeutically used steroids in CV-1 cells: a comparison of their glucocorticoid and mineralocorticoid properties. European Journal of Endocrinology (In press).

Received 23 April 2004

Accepted 3 May 2004 